\title{
Breast reduction surgery in Ontario: Changes in practice, 1992 to 2008
}

\author{
Bisher AlShanawani MD1,2, Nawarah ALArfaj MD², ${ }^{2,}$ Feras AlShomer MD², \\ Muhammad Mamdani MPH MA Pharm D ${ }^{4}$, Tara Gomes MHSC ${ }^{5}$, James Mahoney MD FRCSC ${ }^{6}$
}

\begin{abstract}
B AlShanawani, N ALArfaj, F AlShomer, M Mamdani, T Gomes, J Mahoney. Breast reduction surgery in Ontario: Changes in practice, 1992 to 2008. Can J Plast Surg 2013;21(1):41-44.
\end{abstract}

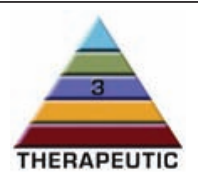

BACKGROUND: Symptomatic mammary hypertrophy impacts physical function and patient quality of life. Breast reduction mammoplasty, a surgical procedure performed to reduce breast size, has been used for many years to reduce these symptoms.

OBJECTIVE: To evaluate variations in the surgical practice of breast reduction mammoplasty among women $\geq 15$ years of age (approximately 6.4 million population in 2008) over a 17-year period in Ontario.

METHOD: A population-based, cross-sectional time series analysis was conducted to examine temporal trends in 87,049 breast reduction surgeries performed between January 1, 1992 and December 30, 2008.

RESULTS: Breast reduction rates have been relatively stable over time, with 83 per 100,000 of the female population undergoing breast reduction surgery annually. However, a significant decrease in the rate of inpatient surgeries were observed over the study period (from 69.3 per 100,000 in 1992 to 25.7 per 100,000 in 2008). At the beginning of the study period, the highest annual rates of this procedure were observed among women 21 to 30 years of age ( 116.6 procedures per 100,000); however, by the end of the observation period, this shifted to women 31 to 50 years of age (109.9 procedures per 100,000$)$. Furthermore, the annual procedure rate among women $\geq 51$ years of age almost doubled, rising from 36.4 procedures per 100,000 in 1992 to 66.6 procedures per 100,000 in 2008. This was likely related to changing demographics and social factors.

CONCLUSION: These data suggest that breast reduction mammoplasty will continue to be requested, with an increased proportion of patients who are older and desire improved quality of life and physical function.

Key Words: Breast; Canada; Epidemiology; Mammary hypertrophy; Reduction

Symptomatic mammary hypertrophy has a major impact on physical $\checkmark$ function and patient quality of life (1). The significant weight of hypertrophic breasts may be a cause of functional disability (1), especially during exercise in which localized pain and discomfort result from brassiere straps abrading or irritating the skin (1). Breast reduction mammoplasty, a surgical procedure performed to reduce breast size, has been used for many years to reduce these symptoms and improve associated quality of life (2). The principles of the surgery include volume reduction and skin laxity correction, where necessary, to improve symptoms while preserving breast function. This procedure has been associated with high patient satisfaction (3), improved quality of life, enhanced body perception and improvement of clinical depression symptoms. Studies evaluating patient safety and risk for cancer after reduction surgery have demonstrated no increased risk of breast cancer, and have even suggested a decreased risk in women who underwent the procedure (4-6). Breast reduction mammoplasty is performed quite frequently; however, there are several reasons why trends in breast surgery rates may have changed over time. These include variable criteria in patient selection, development of alternative therapies,

\section{La chirurgie de réduction mammaire en Ontario : les changements de pratique de 1992 à 2008}

\begin{abstract}
HISTORIQUE : L'hypertrophie mammaire symptomatique nuit à la fonction physique et à la qualité de vie des patientes. La mammoplastie par réduction mammaire, une intervention chirurgicale visant à réduire la dimension des seins, est utilisée depuis de nombreuses années pour réduire ces symptômes.
\end{abstract}

OBJECTIF : Évaluer les variations de la pratique chirurgicale de mammoplastie par réduction mammaire chez les femmes de 15 ans ou plus (population d'environ 6,4 millions de personnes en 2008) sur une période de 17 ans en Ontario.

MÉTHODOLOGIE : Les chercheurs ont procédé à une analyse transversale en population de séries chronologiques pour examiner les tendances temporelles de 87049 chirurgies de réduction mammaire exécutées entre le $1^{\text {er }}$ janvier 1992 et le 30 décembre 2008.

RÉSULTATS : Les taux de réduction mammaire sont relativement stables dans le temps, 83 femmes sur 100000 subissant ce type d'opération chaque année. Cependant, on observe une diminution significative du taux d'opérations avec hospitalisation pendant la période de l'étude (de 69,3 cas sur 100000 en 1992 à 25,7 cas sur 100000 en 2008). Au début de la période de l'étude, le taux annuel d'interventions le plus élevé s'observait chez les femmes de 21 à 30 ans (116,6 interventions sur 100 000). Cependant, à la fin de la période d'observation, ce taux était passé aux femmes de 31 à 50 ans $(109,9$ interventions sur 100 000). De plus, le taux annuel d'interventions chez les femmes de 51 ans ou plus avait presque doublé, passant de 36,4 interventions sur 100000 en 1992 à 66,6 interventions sur 100000 en 2008. Ce phénomène était probablement lié à la modification de la démographie et à des facteurs sociaux.

CONCLUSION : D'après ces données, la mammoplastie par réduction mammaire continuera d'être recherchée, mais par une plus grande proportion de patientes plus âgées qui désirent améliorer leur qualité de vie et leur fonction physique.

and increased knowledge of the risks and benefits of the procedure. Furthermore, there has also been a focus on reducing the cost of surgery. As a result, there has been a general shift toward performing procedures in outpatient setting as opposed to an outpatient setting. Moreover, the surgical technique has been modified to reduce blood loss and treat pain, leading to expedited discharge $(7,8)$.

Although many clinical studies on breast reduction have been published, they have generally examined small patient cohorts and relatively little has been published on population-based trends in breast reduction surgery. The objective of the present study was to determine the prevalence and performance of breast reduction surgery among women $\geq 15$ years of age over a 17 -year period in Ontario.

\section{METHODS}

A population-based, cross-sectional time series analysis using linked administrative health care databases in Ontario was performed to examine temporal trends in breast reduction surgery among women $\geq 15$ years of age from 1992 through 2008. In 2008, Ontario had a population of approximately 13 million, of whom approximately 6.4 million were

${ }^{1}$ St Michael's Hospital, Toronto, Ontario; ${ }^{2}$ King Saud University/King Saud University College of Medicine, Riyadh, Saudi Arabia; ${ }^{3}$ University of Toronto; ${ }^{4}$ Applied Health Research Centre (AHRC) Li Ka Shing Knowledge Institute of St Michael's Hospital; ${ }^{5}$ Ontario Drug Policy Research

Network, Institute For Clinical Evaluative Sciences; ${ }^{6}$ Division of Plastic $\mathcal{E}$ Reconstructive Surgery, St Michael's Hospital, Toronto, Ontario

Correspondence: Dr Bisher AlShanawani, King Saud University/King Saud University College of Medicine, Riyadh, Saudi Arabia.

Telephone 96-650-548-0950, fax 96-614-67-9493, e-mail bishersh@hotmail.com 
Figure 1) Rates of the total number of breast reduction surgery procedures performed in females $\geq 15$ years of age in Ontario

women $\geq 15$ years of age. Residents of Ontario have universal access to health care services, including breast reduction surgery, if they demonstrate a medical indication for the procedure. The present study was approved by the Ethics Review Board of Sunnybrook Health Sciences Centre, Toronto, Ontario.

The study time frame was divided into 68 quarterly intervals from January 1, 1992 to December 30, 2008. Eligible subjects were female Ontario residents $\geq 15$ years of age who were alive at the beginning of each quarter with medical reasons qualifying the surgical procedure. The Ontario Health Insurance Plan (OHIP) database, which captures physicians' billing claims for services provided to residents of Ontario, was used to identify patients undergoing breast reduction surgery using a specific fee code for breast reduction; women undergoing such procedures for nonmedical necessities were not included in the database. Inpatient surgeries were identified using the Canadian Institute of Health Information Discharge Abstract Database, which captures diagnoses and procedures of patients admitted to hospitals. If a surgery identified in the OHIP database was billed during a hospital stay, the surgery was classified as 'inpatient'. These databases contain specific procedure and billing codes for breast reduction surgery. Duplicate records, which were defined as records with the same unique encrypted identifier and procedure date, were excluded. Records with missing unique encrypted identifiers were also excluded. Demographic and vital statistics data were captured using the Registered Persons Database.

To obtain rates of breast reduction surgery procedures, the total number of procedures conducted during the quarter among all Ontarian women alive at the beginning of the quarter were assessed. Rates were presented as the number of procedures per 100,000 women. As secondary analyses, breast surgery reduction procedure rates as a function of age group (grouped as 15 to 20 years, 21 to 30 years, 31 to 50 years, and $\geq 51$ years of age) and whether the procedure involved an overnight hospital stay or was performed as a day surgery, was examined.

Time series analysis involving autoregressive integrated moving average models and exponential smoothing models were used to evaluate changes in quarterly breast reduction surgery procedures over the study period. Stationarity was assessed using the autocorrelation function and the augmented Dickey Fuller test. The autocorrelation, partial autocorrelation and inverse autocorrelation functions were used to model parameter appropriateness and seasonality. The presence of white noise was assessed by examining the autocorrelation at various lags using the jung-Box $\chi^{2}$ statistic. Analyses were performed using SAS version 9.1 (SAS Institute, USA).

\section{RESULTS}

Between 1992 and 2008, 87,049 breast reduction procedures among women $\geq 15$ years of age were conducted in Ontario, with an average of 5121 procedures conducted per year. The study population ranged

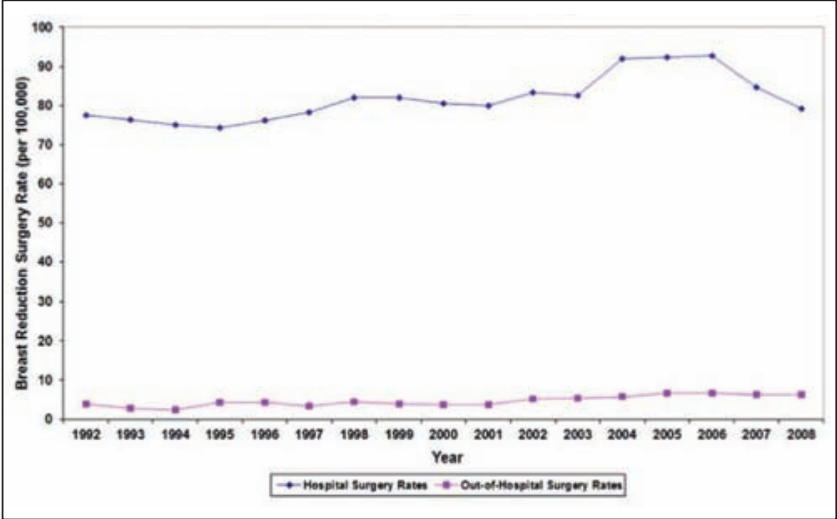

Figure 2) Breast reduction surgery rates stratified according to hospital versus out-of-hospital procedures

from approximately 5.4 million women in 1992 to 6.4 million at the beginning of 2008. The procedure rate was relatively stable over this time period $(\mathrm{P}=0.97)$, with an average rate of 86.4 procedures per 100,000 women (Figure 1). Approximately 83 women undergo breast reduction surgery annually per 100,000 population. The average annual rate of procedures conducted in a hospital setting was approximately 18 -fold higher than that of procedures conducted outside a hospital setting (81.7 versus 4.7 per 100,000 women) (Figure 2). The rates of procedures conducted in a hospital setting were relatively stable over the study period $(\mathrm{P}=0.97)$, with a modest yet statistically significant increase in the rate of procedures conducted outside of a hospital setting (3.9 per 100,000 in 1992 to 6.3 per 100,000 in $2008 ; \mathrm{P}<0.01$ ). The rate of breast reduction surgery procedures requiring an overnight hospital stay decreased significantly from 71.7 per 100,000 in 1992 to 25.9 per 100,000 in $2008(\mathrm{P}<0.001)$. Conversely, the rate of same-day breast reduction surgery procedures not requiring an overnight hospital stay increased significantly from 9.6 per 100,000 in 1992 to 59.6 per 100,000 in $2008(\mathrm{P}<0.001)$ (Figure 3).

Differences in the rates of breast reduction surgery procedures were also observed as a function of age (Figure 4). At the beginning of the observation period, the highest annual rate of breast reduction surgery procedures was observed among women 21 to 30 years of age (116.6 procedures per 100,000 ). By the end of the study period, however, the highest annual rates of procedures had shifted to women 31 to 50 years of age ( 109.9 procedures per 100,000$)$. At the end of the study period, the procedure rates for women 15 to 20 and 21 to 30 years of age were 66.4 and 81.6 procedures per 100,000 , respectively. A significant increase in the rates of surgical procedures was observed for women $\geq 51$ years of age, almost doubling from 36.4 procedures per 100,000 in 1992 to 66.6 procedures per 100,000 in $2008(\mathrm{P}<0.01)$. Among women 21 to 30 years of age, a stable breast reduction surgery procedure rate was observed until 2004, after which a significantly decreasing trend was observed $(\mathrm{P}<0.01)$. Finally, breast reduction surgery rates among women 15 to 20 years of age decreased significantly from 94.1 procedures per 100,000 in 1992 to 66.4 procedures per 100,000 in $2008(\mathrm{P}<0.01)$.

\section{DISCUSSION}

Women with medical indications necessitating breast reduction surgery are eligible for consideration and, when approved, all aspects of the surgery are covered by OHIP. Criteria for breast reduction surgery coverage in Ontario remained the same over the study period. Indications include symptoms of pain in the back, neck and shoulders, bra strap grooving and inframammary dermatitis/intertrigo (9). Authorization in advance of the procedure is obtained by the surgeon performing the procedure with documentation of symptoms and findings. This process did not change over the study period. Most surgeries were performed in provincially funded hospitals. 
Figure 3) Breast reduction surgery rates stratified according to inpatient hospitalizations and day surgeries

Out-of-hospital procedure rates increased only marginally over time, with no major changes over the study period (Figure 2). However, the duration of hospital stay changed substantially over the study period, such that same-day procedures have been performed more frequently than those requiring in-patient hospitalizations since 2003 (Figure 3). This reflects a change in practice that is related to advances in perioperative care, including appropriate patient selection, anesthesia and pain management (10), as well as increased availability of postoperative professional home care services. Because the safety of this procedure performed in outpatient settings has been demonstrated, with no change in outcomes or complications (11-13), the length of stay has been reduced, thus directly affecting the total cost of the procedure (11). There may be additional potential for reducing the length of hospital stay in patients undergoing breast reduction surgery, especially in younger age groups who are good candidates for this approach. Additional modifications to the perioperative process, including surgical techniques, will further reduce costs.

The present study showed a decrease in the procedure rates among women 15 to 30 years of age (Figure 4). This reduction may be explained by the more recent focus on healthier lifestyles and the positive effects of exercise and diet modification on symptoms. Changes in the perception of ideal body image related to breast size over time (14) may also be a factor, with some women exploring nonsurgical options to treat the problem. For women 15 to 20 years of age, surgeon hesitation or preference to delay this procedure until a later age may also play a role in the decreasing trend observed. Women 21 to 30 years of age (the childbearing age) may desire to delay the procedure until they have had their family to avoid any potential effect on breastfeeding. An annual increase in the rate of breast reduction surgeries among women 31 to 50 years of age (Figure 4), who represent the highest procedure rate, may be partially explained by the development of other musculoskeletal problems. In addition, increased awareness of the procedure, changes in breast size following child bearing as well as the encouraging high satisfaction rates of women who previously underwent the surgery may affect the willingness to undergo this procedure. There may also be less concern for potential surgical side effects including changes in nipple sensitivity, surgical scars and undergoing anesthesia.

Physical symptoms, which are more pronounced in older women who contend with the constant weight of heavily pendulous breasts (15), may explain the gradually increasing number of older women ( $\geq 51$ years of age) who undergo this procedure (Figure 4 ). Emphasis on activity and health, as well as better communication strategies concerning the benefits of the procedure, may also play a role. In addition, body mass index in this age group has been rising, which may also have contributed to the increase in the number of procedures (16).

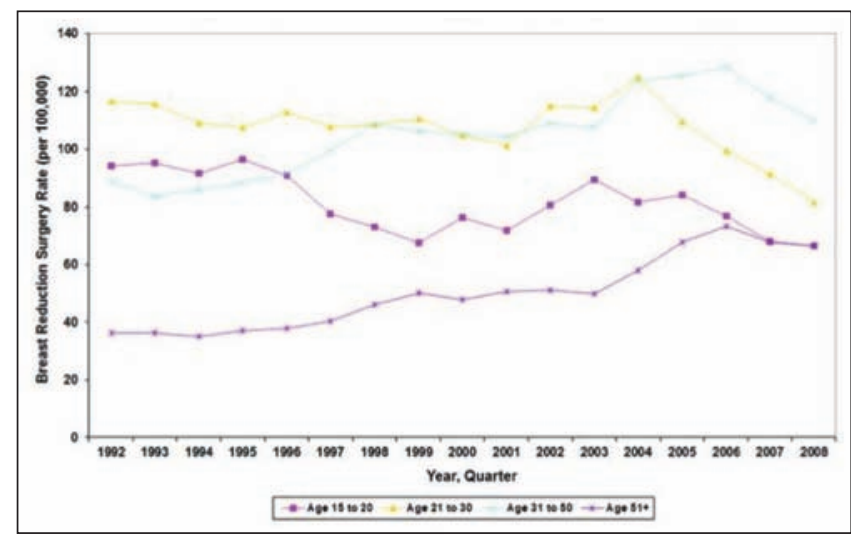

Figure 4) Yearly breast reduction surgery rates stratified according to age

We noted a difference between the number of procedures performed and the number of patients who underwent surgery. This may reflect surgical revisions or separate operations on different days.

The data provided in the present study could act as a baseline for comparison with other jurisdictions and health providers where reduction mammoplasty is performed, and may be useful in the planning of resource allocation. The criteria used for patient selection in the present study are widely accepted. A recent evaluation of similar criteria for patient selection demonstrated the lack of scientific evaluation of signs and symptoms of patients undergoing breast reduction surgery as well as the variation in the breast size of patients who report positive outcomes after surgery. The procedure rate was relatively stable over the 17 -year study period (Figure 1), with an average annual rate of 83 women per 100,000 undergoing the surgery. This suggests that the incidence of breast hypertrophy is stable and that the proportion of the population undergoing breast reduction mammoplasty will remain the same unless significant change in breast size occurs or different criteria are used for assessing eligibility for insurance coverage.

Cost analysis and resource planning for this condition, potentially improving patients' outcome and delivery of care, is becoming increasingly important. Although fluctuations among different age groups exist, the overall prevalence of breast reduction has remained the same, which is likely due to the consistent criteria for full coverage of this surgery implemented by OHIP over the study period. Changes to these criteria could substantially affect the overall cost for this procedure at a population level.

Limitations of the present study include the nature of the data available for analysis. Unfortunately, data regarding original breast size, side orientation and the amount of breast tissue removed, together with details regarding the length of hospital stay, were not available in the databases used in the present study. To our knowledge of clinical practice in our region, the criteria for selecting patients undergoing breast reduction surgery remained unchanged during the course of the study. Similarly, the actual surgical technique of breast reduction was not available. Based on the experience of the senior author, there has been variation in breast reduction mammoplasty techniques that are related to surgeon experience and preference.

\section{CONCLUSION}

The prevalence of breast reduction surgeries in the population of Ontario remained constant over this particular 17-year period; however, there has been a marked shift to perform the procedure as a day surgery as opposed to surgery requiring hospitalization. The present study showed a substantial variation in women's ages over time, with an increase in the procedure rate among older age groups and a decrease in younger women. This suggests that breast reduction surgery may be requested more often as the population ages and women desire improvement in quality of life and function. 


\section{REFERENCES}

1. Smith MM, Kent KM. Breast concerns and lifestyles of women. Clin Obstetr Gynecol 2002;45:1129-39.

2. Blomqvist LMD, Brandberg YP. Three-year follow-up on clinical symptoms and health-related quality of life after reduction mammaplasty. Plast Reconstr Surg 2004;114:49-54.

3. Woodman R, Radzyminski S. Women's perception of life following breast reduction: A phenomenological study. Plast Surg Nurs 2009;29:39-46.

4. Brown MH, Weinberg MB, Chong NB, Levine RMD, Holowaty EM. A cohort study of breast cancer risk in breast reduction patients. Plast Reconstr Surg 1999;103:1674-81.

5. Boice JD Jr, Persson I, Brinton LA, et al. Breast cancer following breast reduction surgery in Sweden. Plast Reconstr Surg 2000;106:755-62.

6. Fryzek JP, Ye W, Nyren O, Tarone RE, Lipworth L, McLaughlin JK. A nationwide epidemiologic study of breast cancer incidence following breast reduction surgery in a large cohort of Swedish women. Breast Cancer Res Treat 2006;97:131-4.

7. Kryger ZBM, Rawlani VB, Lu LM, Fine NAM. Decreased postoperative pain, narcotic, and antiemetic use after breast reduction using a local anesthetic pain pump. Ann Plast Surg 2008;61:147-152.

8. Wilmink HM, Spauwen PH, Hartman EH, Hendriks JC, Koeijers VF. Preoperative injection using a diluted anesthetic/adrenaline solution significantly reduces blood loss in reduction mammaplasty. Plast Reconstr Surg 1998;102:373-6.
9. Nguyen JT, Wheatley MJ, Schnur PL, Nguyen TA, Winn SR. Reduction mammaplasty: A review of managed care medical policy coverage criteria. Plast Reconstr Surg 2008;121:1092-100.

10. Culliford AT, Spector JA, Flores RL, Louie O, Choi M, Karp NS. Intraoperative sensorcaine significantly improves postoperative pain management in outpatient reduction mammaplasty. Plast Reconstr Surg 2007;120:840-4.

11. Davies BW, Lewis RD, Pennington GA. Reduction mammaplasty: A comparison of outpatient and inpatient procedures. Aesthetic Plast Surg 1996;20:77-80.

12. Stevens WG, Gear AJ, Stoker DA, et al. Outpatient reduction mammaplasty: An eleven-year experience. Aesthet Surg J 2008;28:171-9.

13. Short KK, Ringler SL, Bengtson BP, Hunstad JP, Henry E. Reduction mammaplasty: A safe and effective outpatient procedure. Aesthetic Plast Surg 1996;20:513-8.

14. Martin JBP. The development of ideal body image perceptions in the United States. Nutrition Today May/June 2010;45:98-110.

15. Heddens CJ. Breast reduction for the older woman. Plast Surg Nurs 2000;20:141-3, 170.

16. Sugawara AR, Yanagishita JM, Sano AP, et al. Body image: International comparisons: From the Symposium Held at the 15 th International Congress of Dietetics. Nutr Today 2010;45:113-7. 